\title{
Graphical user authentication algorithm for mobile banking user
}

\begin{abstract}
The literature study conducted on the adoption of mobile banking services revealed that the common mode of username and password has been a cognitive burden for users playing a role in hindering them to adopt or adapt to mobile banking. The literature study conducted shows that the graphical user authentication algorithm could be a suitable algorithm to be used for mobile banking. Therefore, a preliminary study was conducted to strengthening the suitability of the graphical user authentication for the mobile banking. At the end of this study, results show that respondents are willing to try out a new mobile banking user authentication algorithm and the graphical user authentication algorithm could be a suitable algorithm for mobile banking.
\end{abstract}

Keyword: Graphical user authentication algorithm; Mobile banking 